\title{
SOLUÇÕES BASEADAS NA NATUREZA (SBN) E DRENAGEM URBANA EM CIDADES LATINO-AMERICANAS DESAFIOS PARA IMPLEMENTAR SOLUÇÕES FLUIDAS EM AMBIENTES RÍGIDOS
}

Valéria Nagy de Oliveira Campos

\section{RESUMO}

Este artigo tem como tema a adoção de soluções baseadas na natureza ( $\mathrm{SbN}$ ) na drenagem de águas pluviais em cidades da América Latina, considerando que as $\mathrm{SbN}$ prestam serviços ambientais e contribuem para tornar as cidades mais resilientes. Pondera que, como evidenciado pelo confronto entre a realidade do setor e o desejável para sua adoção, existem questões a enfrentar tais como a falta de visão sistêmica na estrutura governamental e a inadequação do arranjo institucional responsável pelo setor. Objetivando aprofundar a reflexão sobre a adoção de SbN, em especial do ponto de vista da ação governamental em bacias "metropolizadas", adota-se São Paulo e Cidade do México como estudos de caso. Tal reflexão apoia-se na revisão bibliográfica sobre aspectos conceituais e sobre a difusão e assimilação do tema na América Latina, bem como no exame de documentos relacionados à adoção de SbN na drenagem urbana e na adaptação a eventos extremos nas áreas de estudo. Como resultado, além da identificação dos desafios locais, a pesquisa indica como oportunidade aberta a existência do Comitê de Bacia Hidrográfica Alto Tietê e do Consejo de Cuenca del Valle de México, os quais podem incorporar o tema de modo mais incisivo em sua pauta. Aponta ainda que aproveitar esta oportunidade trará ganhos ao processo: por um lado, pode-se valer da experiência destes arranjos com processos participativos e, por outro, com a adoção de processos de cocriação, pode-se aprimorar os procedimentos destes colegiados e, por extensão, a governança. Contudo, o cenário, embora favorável, ainda está sendo delineado.

\section{Palavras-chave}

Soluções baseadas na natureza - SbN; Adaptação; Drenagem urbana; Cocriação; Governança 


\title{
SOLUCIONES BASADAS EN LA
}

NATURALEZA (SBN) Y DRENAJE

URBANO EN LATINOAMÉRICA

\author{
RETOS PARA IMPLEMENTAR \\ SOLUCIONES FLUIDAS EN \\ AMBIENTES RIGIDOS
}

Valéria Nagy de Oliveira Campos

\section{RESUMEN}

Este artículo tiene como tema la adopción de soluciones basadas en la naturaleza (SbN) en el drenaje urbano en América Latina. Considera que las SbN prestan servicios ambientales y contribuyen para aumentar la resiliencia de las ciudades. Asimismo, considera que, como lo evidencia el enfrentamiento entre la realidad del sector y lo deseable para su adopción, existen temas a enfrentar como la falta de visión sistémica en la estructura de gobierno y la inadecuación del arreglo institucional responsable del sector. Con el objetivo de profundizar la reflexión sobre la adopción de SbN, especialmente desde el punto de vista de la acción del gobierno en las cuencas "metropolizadas", se adoptan como casos de estudio São Paulo y Ciudad de México. Dicho análisis está respaldado por la revisión de la literatura sobre aspectos conceptuales y sobre la difusión y asimilación del tema en América Latina, así como en el examen de documentos relacionados con la adopción de SbN en el drenaje urbano y la adaptación a eventos extremos en las áreas de estudio. Como resultado, además de identificar los desafíos locales, la investigación señala como una oportunidad abierta la existencia del Comité de Cuenca del Alto Tietê y el Consejo de Cuenca del Valle de México, que pueden incorporar de manera más incisiva el tema en su agenda. El análisis indica también que aprovechar esta oportunidad traerá ganancias a lo largo del proceso: por un lado, se puede aprovechar la experiencia de estas instancias con procesos participativos y, por otro, la adopción de procesos de co-creación puede mejorar los procedimientos de estos órganos colegiados y, por extensión, la gobernanza. Sin embargo, el escenario, aunque favorable, aún se está perfilando.

\section{Palabras clave}

Soluciones basadas en la naturaleza -SbN; Adaptación; Drenaje urbano; Co-creación; Gobernanza 


\title{
NATURE-BASED SOLUTIONS (NBS) AND URBAN DRAINAGE IN LATIN AMERICA \\ CHALLENGES TO IMPLEMENT FLOW SOLUTIONS INSIDE AN INFLEXIBLE ARRANGEMENT
}

Valéria Nagy de Oliveira Campos

\begin{abstract}
This article focuses on the adoption of nature-based solutions (NbS) to address rainwater drainage in Latin American cities. It considers that the NbS provide environmental services and contribute to making cities more resilient. It also ponders that, as evidenced by the confrontation between the reality of the sector and what is desirable for their adoption, there are issues to be faced, such as the lack of systemic vision in the government structure and the inadequacy of the institutional arrangement responsible for the sector. Aiming to deepen the reflection on the adoption of NbS, especially from the point of view of government action in "metropolized" basins, São Paulo and Mexico City are adopted as case studies. This analysis is supported by the literature review on conceptual aspects and on assimilation of the theme in Latin America, as well as on the assessment of documents that concern the use of NbS in urban drainage and adaptation to extreme events in these areas. As a result, in addition to identifying local challenges, the research indicated as an open opportunity the existence of the Alto Tietê River Basin Committee and the Mexico Valley Basin Council, which can incorporate the topic more incisively into their agenda. It is considered that taking advantage of this opportunity will bring gains throughout the process: on the one hand, these arrangements already have experience in participatory processes, and, on the other hand, the adoption of co-creation processes can improve the procedures of these committees and, by extension, the governance. However, the scenario, although favorable, is still being outlined.
\end{abstract}

\section{Keywords}

Nature-based solutions - NbS; Adaptation; Urban drainage; Co-creation; Governance 
1. Enquanto serviços ecossistêmicos referem-se aos benefícios gerados pelos ecossistemas para a sociedade, em termos de manutenção, recuperação ou melhoria das condições ambientais, serviços

ambientais referem-se aos benefícios gerados por atividades humanas, individuais ou coletivas, que favorecem a conservação ou melhoria dos ecossistemas.

2. A infraestrutura verde, também conhecida como infraestrutura de baixo impacto - lowimpact development - LID, em inglês (University of Arkansas

Community Design Center [UACDC], 2010) -, envolve diferentes soluções: alagados construídos, jardins de chuva, canteiros pluviais, biovaletas.

\section{INTRODUÇÃO}

Uma das questões cruciais a ser enfrentada, na atualidade, refere-se aos impactos dos eventos extremos decorrentes das mudanças climáticas, como inundações, secas e ondas de calor, que estão ocorrendo com maior frequência e intensidade em diferentes áreas do planeta. Tais eventos são sentidos de modo mais efetivo pela população local e pelas infraestruturas urbanas, pondo a resiliência das cidades à prova. Isto fica mais evidente especialmente nas bacias urbanizadas - e metropolizadas - em que às incertezas soma-se a complexidade decorrente da sobreposição de escalas, interferências administrativas, dentre outros conflitos.

Trata-se de uma questão transversal que demanda uma mudança de paradigma na relação homem e natureza, apoiada mais na convivência do que no domínio, a qual deve incidir na gestão das águas, de modo geral, e na drenagem urbana, de modo particular. Entretanto, adotar uma abordagem sistêmica não implica apenas uma decisão técnica; requer, sobretudo, vontade política e social.

Nos países do chamado Sul Global, como os da América Latina, este assunto se amplifica uma vez que os impactos destes eventos nos sistemas natural e humano agregam-se aos intricados problemas socioambientais, econômicos e políticos pré-existentes, acirrados pela pandemia de Covid-19.

Contudo, apesar desta conjuntura, é possível identificar que alguns governos nacionais e subnacionais têm elaborado políticas públicas objetivando alterar este cenário, mesmo que às vezes os resultados fiquem aquém do esperado. Como exemplos, tem-se propostas para cidades mais resilientes e sustentáveis e planos de adaptação a eventos extremos.

Neste contexto, vêm ganhando destaque as soluções baseadas na natureza - SbN, conceito guarda-chuva que abrange diferentes opções técnicas, caracterizadas por serem multifuncionais, multiescalares e adaptativas, que prestam importantes serviços ambientais ${ }^{1}$ (Cohen-Shacham, Walters, Janzen, \& Maginnis, 2016).

No caso da drenagem urbana, um tipo de SbN utilizado é a infraestrutura verde ${ }^{2}$ que contribui para adaptar as áreas urbanizadas para que acomodem melhor as águas pluviais, colaborando para a requerida resiliência urbana. Normalmente utilizada de modo complementar à infraestrutura convencional, a infraestrutura verde permite, por exemplo, diminuir o escoamento superficial, sobrecarregando menos o sistema de drenagem instalado; controlar a poluição difusa; aumentar a área filtrante; para citar alguns benefícios. Isto ocorre porque, ao contrário do sistema convencional, o sistema baseado em SbN trata a questão na origem, por meio da implementação de um conjunto de 
intervenções de menor porte, localmente adaptadas e conectadas em rede, promovendo uma convivência maior e melhor entre o espaço urbanizado e a natureza e proporcionando múltiplos benefícios ${ }^{3}$ (Pellegrino \& Moura, 2017).

Não obstante estes aspectos positivos, existem desafios a enfrentar para ampliar sua implementação na drenagem urbana, de modo efetivo, especialmente no que diz respeito à atuação governamental, responsável pela regulação do setor e pela efetivação de ações estruturais e não estruturais. Um destes desafios é a falta de visão sistêmica na abordagem da questão por parte dos tomadores de decisão. Outro desafio, em parte decorrente do anterior, refere-se às características das estruturas administrativas que tratam desta matéria, direta ou indiretamente, geralmente dispersas e resistentes a mudanças. Outro ponto desafiador relaciona-se ao processo de planejamento e gestão deste serviço, pouco aberto à participação de outros setores, que não técnico ou político, o que restringe a abordagem e reduz o escopo.

Para melhores resultados, as SbN carecem uma abordagem sistêmica que conduza à integração das propostas de diferentes setores e níveis de governo, considerando as diferentes escalas abrangidas e maior participação dos beneficiários, diretos ou indiretos. Além disto, dadas suas características e a incerteza dos eventos envolvidos, requerem um ambiente flexível e adaptativo que responda na medida das demandas.

O confronto entre a realidade do setor e o desejável para a adoção de SbN na drenagem aponta, porém, para uma incompatibilidade que necessita ser equacionada.

Estudos recentes (Cohen-Shacham et al., 2016; McCormick, 2020; Morello et al., 2018) indicam a incorporação de inovações nos processos de construção de projetos, como um caminho a ser seguido; factível na medida em que houver um arranjo permeável a tais novidades, no qual as responsabilidades sejam compartilhadas e os processos de cocriação e governança colaborativa estejam envolvidos, ao contrário do observado no setor hoje. Por isto, entende-se que a existência de colegiados, criados para a gestão integrada de recursos hídricos, pode representar uma oportunidade para tratar deste assunto e colaborar

3. Além dos benefícios relacionados diretamente à drenagem e aos processos hídricos, a adoção de $\mathrm{SbN}$ pode proporcionar também o aumento da biodiversidade, a melhoria do microclima, a criação de áreas de lazer, para citar outros benefícios. Isto contribui para que sejam vistas como intervenções "sem arrependimento" (Morello, Mahmoud, Gulyurtlu, Boelman, \& Davis, 2018). para resultados mais eficazes.

Neste sentido, este artigo tem como objetivos: refletir sobre o processo de assimilação das $\mathrm{SbN}$ na América Latina e sua repercussão nas políticas públicas relacionadas à drenagem urbana; identificar desafios para sua adoção, em especial do ponto de vista da atuação governamental; e, considerando a hipótese levantada, analisar o potencial dos referidos colegiados para tratar de $\mathrm{SbN}$, incorporando processos de cocriação e governança colaborativa. Para aprofundar a análise, adota, como estudos de caso, São Paulo, assentada na Bacia Hidrográfica do Alto Tietê, Brasil, e a Cidade do México, situada 
4. A Região Metropolitana de São Paulo - RMSP, formalizada, inclui 39 municípios do estado de São Paulo, sendo que o município de São Paulo concentra cerca de 56\% de sua população (estimativas populacionais da Fundação SEADE, março 2021); aproximadamente 70\% da superfície da RMSP está situada na bacia do Alto Tietê (Campos, 2008). A Zona Metropolitana da Cidade do México - ZMCM, por sua vez, inclui as 16 delegações da Cidade do México, que correspondem a $42 \%$ de sua população, além de 59 munícipios do Estado de México (53\% da população) e 21 municípios do Estado de Hidalgo ( $5 \%$ da população) (Campos, 2008; Cidade do México [CDMX], 2016b). no Vale do México, México, as quais fazem parte, respectivamente, do Comitê de Bacia Hidrográfica do Alto Tietê - CBH-AT, instância de caráter consultivo e deliberativo (São Paulo, 1991), e do Consejo de Cuenca del Valle de México - CCVM, instância de coordenação, consulta e acordos (México, 2020a).

O processo de urbanização destas metrópoles foi marcado pelo domínio das águas presentes em seu território, mediante uma série de obras que canalizaram, tamponaram, ou ainda desviaram e represaram rios e, no caso da Cidade do México, também lagos; além disto, para responder à demanda crescente de sua população e da área metropolitana que se formou 4 (Figuras 1 e 2), construiu-se, em cada área, um complexo sistema hidráulico-sanitário que interligou estas bacias hidrográficas às bacias vizinhas (Figuras 3 e 4), visando ora a transposição de água para abastecimento, ora o escoamento de águas servidas, dentre outras funções (Campos, 2001, 2008; Hernández-Espinosa, Otazo-Sánchez, Román-Gutiérrez, \& Romo-Gómez, 2021).

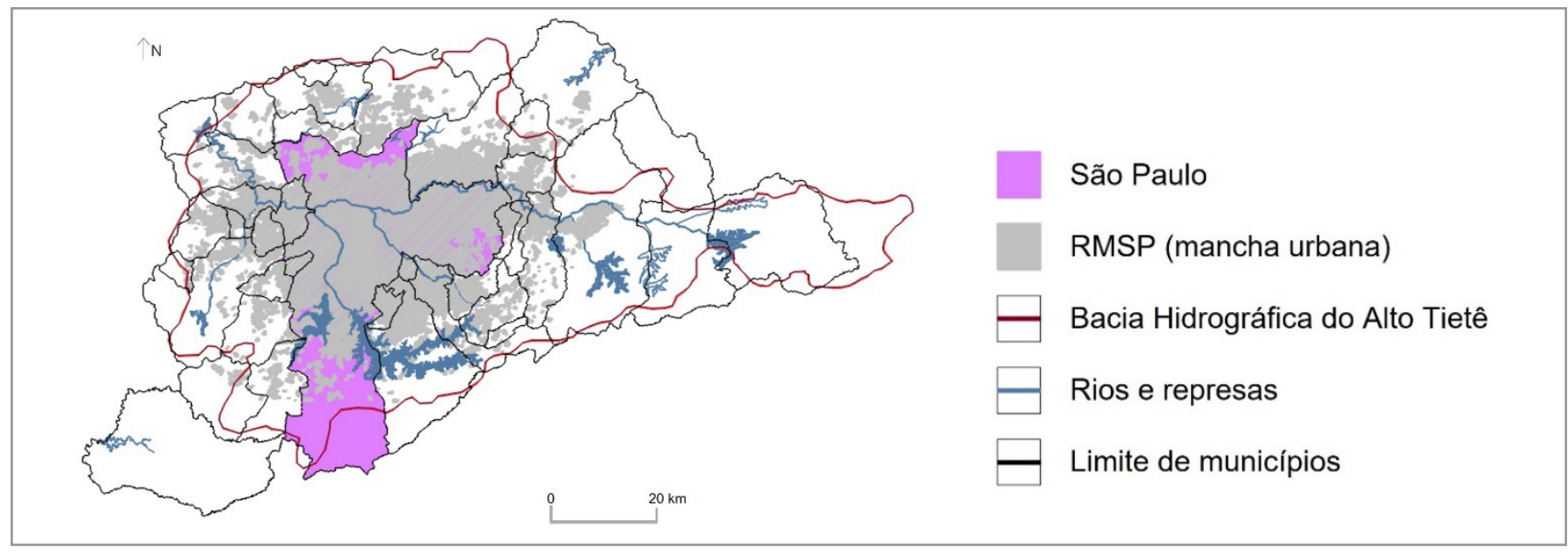

FIGURA 1. Localização de São Paulo na Região Metropolitana de São Paulo e Bacia Hidrográfica do Alto Tietê. Fonte: Elaborado pela autora com base em Campos, 2001, 2008.

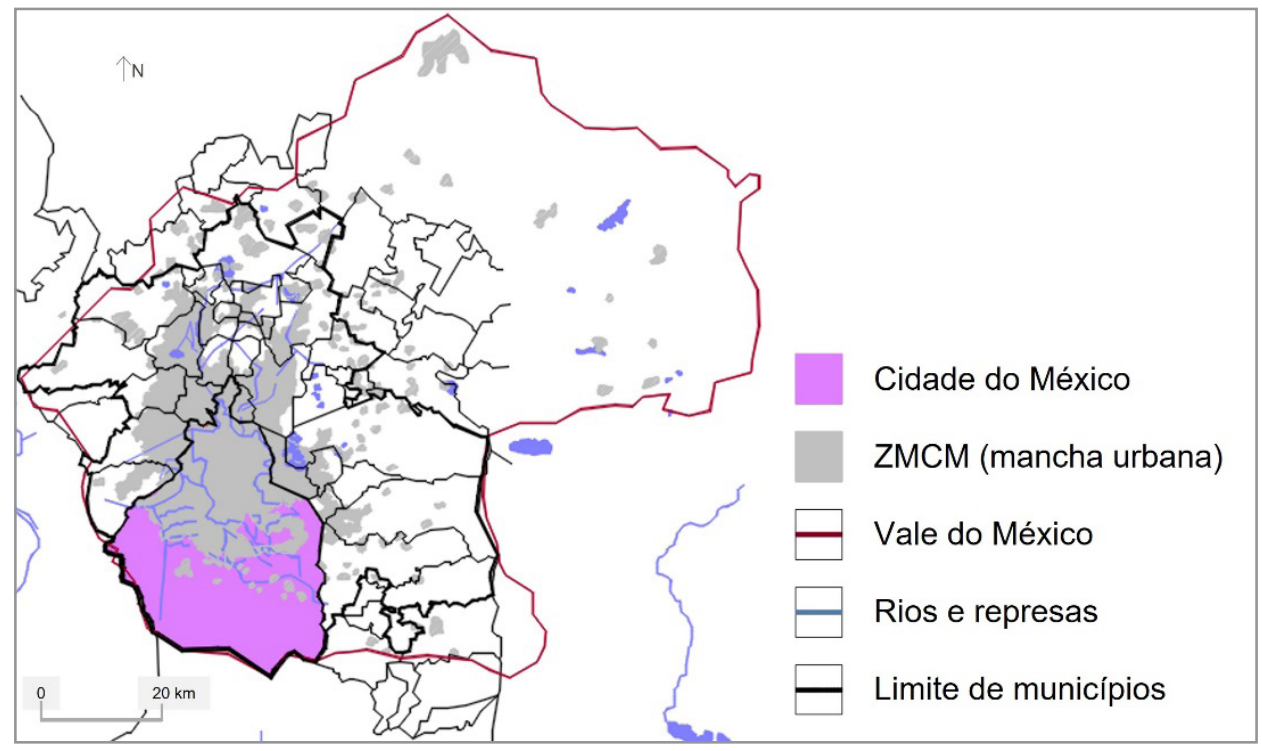

\section{FIGURA 2.}

Localização da Cidade do México na Zona Metropolitana da Cidade do México e Vale do México.

Fonte: Elaborado pela autora com base em Campos, 2001, 2008. 


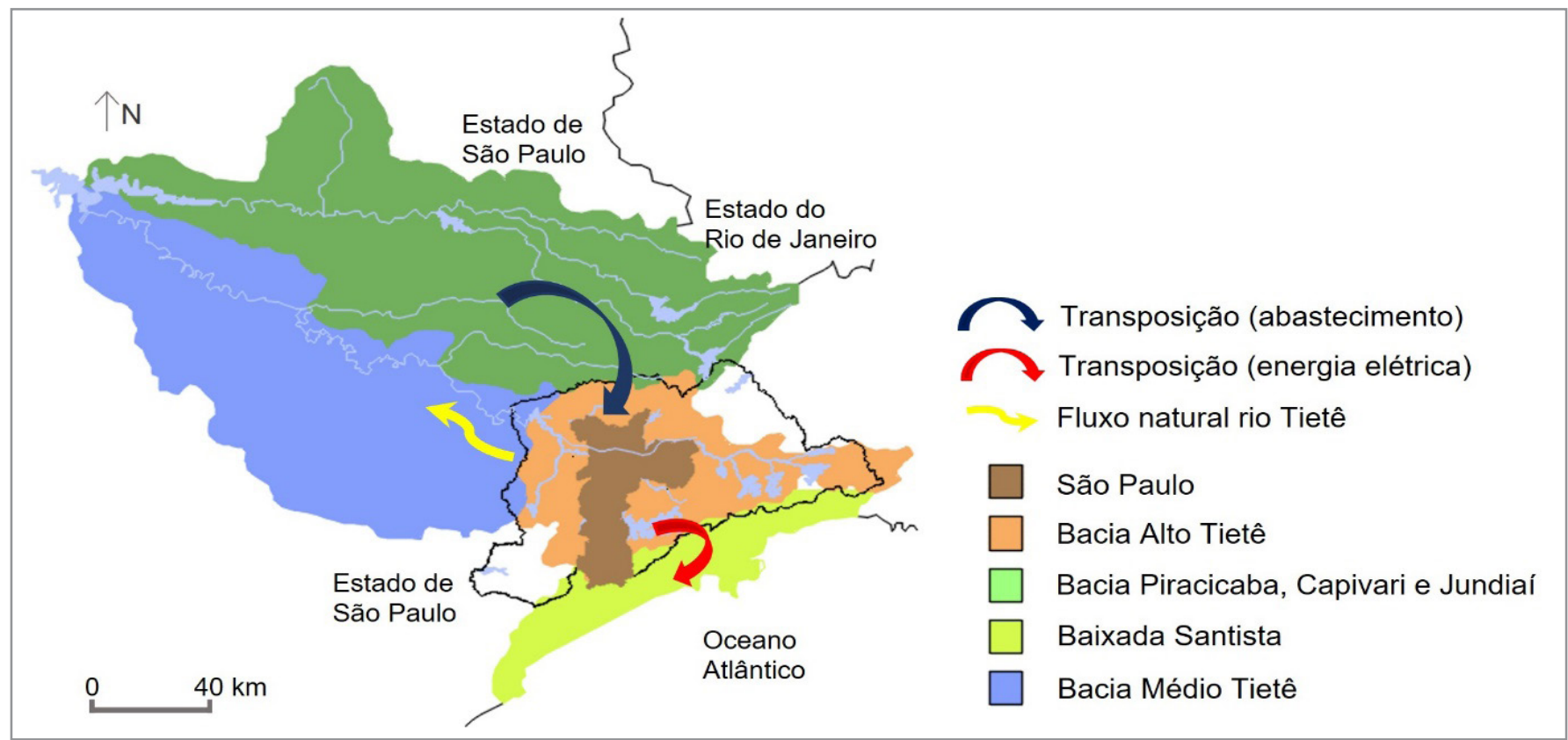

FIGURA 3. Sistema hidráulico-sanitário: interligação das bacias do Alto Tietê, do Médio Tietê, da Baixada Santista e dos rios Piracicaba, Capivari e Jundiaí. Fonte: Elaborado pela autora com base em Campos, 2001, 2008.

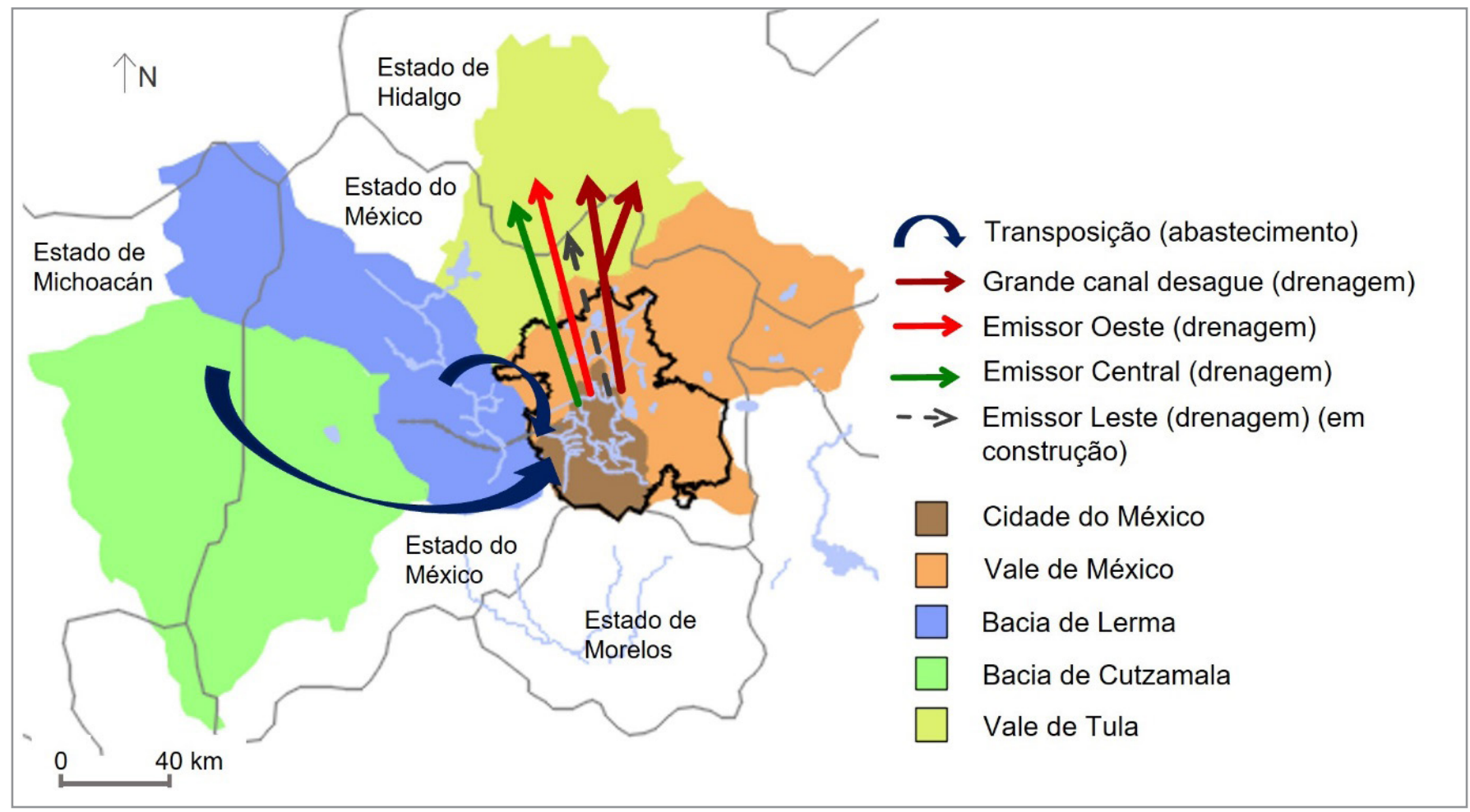

FIGURA 4. Sistema hidráulico-sanitário: interligação das bacias de Cutzamala, Lerma, Vale do México e Vale de Tula. Fonte: Elaborado pela autora com base em Campos, 2001, 2008, e SACMEX, 2016.

O conjunto de obras implementadas para interligação destas bacias, nos dois casos, alterou a dinâmica hidrológica e vem ocasionando uma série de problemas quanto à disponibilidade de água e inundações, que vêm ganhando proporções mais severas.

Em São Paulo, as inundações têm estreita relação com a ocupação intensiva das áreas de várzea e o alto grau de impermeabilização da área 
5. Embora, desde o início do século $X X$, a gestão do saneamento básico seja realizada de modo compartilhado pela Prefeitura e pelo Governo do Estado, a drenagem urbana não tem sido contemplada e as propostas para maior integração institucional não têm sido efetivadas (DAEE, 2014).

6. Em São Paulo, nos anos de 2009, 2010, 2016 e 2020, ocorreram chuvas torrenciais que causaram graves inundações; em contraste, entre 2013 e 2015 , houve grande estiagem que ocasionou séria crise no abastecimento. A Cidade do México, por sua vez, sofreu grave seca entre 2011 e 2013 e em 2018; além disto, anualmente, entre junho e outubro, lida com um período de chuvas intensas que ocasionam inundações. Em 2021, nestas duas áreas, um novo período de estiagem severa se anuncia.

7. O CBH-AT, tripartite, é composto por representantes do governo estadual, dos governos locais - 34 municípios com sede na bacia e dois vizinhos que solicitaram participar -, e da sociedade civil incluídos ambientalistas, academia, representantes das indústrias, etc.

8. O CCVM é composto por representantes do governo federal, dos governos estaduais de Hidalgo, México e Tlaxcala, do governo do Distrito Federal e representantes dos usuários e sociedade civil. urbana. Aqui, o escoamento de águas servidas e de águas pluviais é efetuado de modo separado; a microdrenagem está a cargo da Secretaria Municipal de Infraestrutura e Obras Urbanas e das Subprefeituras regionais, enquanto a macrodrenagem cabe ao Governo do Estado de São Paulo, por meio do Departamento de Águas e Energia Elétrica DAEE$^{5}$. Na Cidade do México, por sua vez, dadas as características da planície lacustre - bacia endorreica -, há décadas vêm sendo construídas grandes estruturas para drenar, de modo combinado, as águas servidas e pluviais. Os serviços de saneamento básico estão a cargo do Sistema de Águas da Cidade do México - Sacmex, órgão da administração direta, sendo que as obras na escala das bacias - como aquelas para transposição - , estão a cargo da Comissão Nacional de Água - Conagua, por meio do Organismo de Cuenca Aguas del Valle de México.

Nos últimos anos, estas áreas vêm sendo impactadas por períodos com severa estiagem, intercalados por períodos com inundações ${ }^{6}, 0$ que tem demandado ações incisivas por parte dos governos; têm colaborado com tal demanda o $\mathrm{CBH}^{-\mathrm{AT}^{7}}$ e o $\mathrm{CCVM}^{8}$, que têm dentre seus objetivos promover ações para combater as causas e efeitos adversos das inundações e das estiagens, bem como integrar ações na defesa contra eventos hidrológicos críticos.

A análise destes casos indica que a inclusão do tema $\mathrm{SbN}$ na pauta destas instâncias pode contribuir para que melhores resultados sejam obtidos pelas ações governamentais voltadas para drenagem urbana, especialmente se tais arranjos tiverem seus papéis e processos aprimorados. Também aponta que, ao tratar esta questão nestes colegiados, pode-se tanto melhorar o processo de seleção e implementação de SbN, considerando a escala da bacia, quanto aprimorar o funcionamento destes arranjos, melhorando a governança da água.

A seguir, são apresentados os materiais e métodos utilizados para desenvolver este trabalho, cujos resultados são apresentados na continuação.

\section{MATERIAIS E MÉTODOS}

Este artigo desenvolveu-se em quatro etapas compreendendo: 1) revisão bibliográfica sobre aspectos conceituais; 2) pesquisa sobre difusão e assimilação do tema na América Latina; 3) análise de documentos relacionados ao assunto com incidência em São Paulo e na Cidade do México e, quando pertinente, na respectiva escala nacional; e 4) reflexão, com base nos resultados alcançados, sobre desafios e oportunidades para adoção de SbN na drenagem urbana nestas áreas, a partir da qual foram elaboradas as considerações finais.

A revisão bibliográfica concentrou-se nas definições e aplicações de SbN (Cohen-Shacham et al., 2016; Fraga \& Sayago, 2020; International Union for Conservation of Nature [IUCN], 2012; McCormick, 2020; 
9. Pesquisa realizada sobre o termo "soluções baseadas na natureza", em inglês, no Google Acadêmico, no período entre 2012 e 2021 (julho), apresentou 14.200 resultados, dos quais cerca de 10.400 entre 2019 e 2021, indicando um aumento considerável do número de publicações e citações sobre o tema nos últimos meses. Contudo, a mesma operação realizada para "SbN na América Latina", em inglês, apresentou apenas 2 resultados, enquanto em espanhol ou português, não houve nenhum resultado, revelando que a publicação de trabalhos científicos sobre o tema na região ainda é incipiente.

10. Dentre elas, destacam-se: Universidade de São Paulo - USP, Universidade Federal de Santa Catarina - UFSC, Universidade Federal do ABC - UFABC, Pontifícia Universidade Católica do Rio de Janeiro - PUC RJ, Universidade Nacional Autônoma do México UNAM, Universidade Autônoma Metropolitana - UAM, Instituto Mexicano de Tecnologia da Água IMTA, e El Colegio de México.
Morello et al. , 2018; Pellegrino \& Moura, 2017) e em sua adoção como estratégia de adaptação a eventos extremos (Delosríos-White, Roebeling, Valente, \& Vaittinen, 2020), a partir de material publicado entre 2012 e $2021^{\prime}$. Adicionalmente, foi levantado material sobre a repercussão do tema em outros campos (United Nations World Water Assessment Programme [WWAP UN-Water], 2018, 2020, 2021) e, dado o viés desta abordagem, material relacionado a processos de inovação, cocriação e governança (Caitana, Ferreira, \& Campos, 2020; Campos \& Fracalanza, 2010; Cavalcante, 2019; Delosríos-White et al., 2020; Morello et al., 2018; Simionato, 2020).

A pesquisa sobre o tema na América Latina focou trabalhos realizados em instituições de ensino e pesquisa relevantes ${ }^{10}$ e relatórios de cooperação técnica, os quais indicaram um aumento na adoção da infraestrutura verde em cidades da região tais como: Bogotá e Lima (Portugal del Pino, Borelli \& Pauleit, 2020), Buenos Aires (World Bank [WB], 2016), Cidade do México (Hernández Solís, 2021), Quito (Yerovi López, 2015), Santiago do Chile (Giannotti, Vásquez, Galdámez, Velásquez, \& Devoto, 2021), Campinas, Rio de Janeiro e São Paulo (Herzog \& Antuña Rozado, 2020).

No que diz respeito às áreas de estudo, foram analisados materiais relacionados à drenagem urbana (Banco Mundial [BM], 2013; Campos, 2001; DAEE, 2014; Hernández-Espinosa et al., 2021; Jiménez-Cisneros, 2011; Perló Cohen \& González Reynoso, 2005; São Paulo, 2019) e às políticas locais de adaptação a eventos extremos (Cidade do México [CDMX], 2014, 2016b; São Paulo, 2021a), que adotam SbN como estratégia, bem como documentos pertinentes às políticas nacionais nas quais encontram respaldo (Brasil, 1997, 2017, 2020; México, 2018, 2020a, 2020b; Ministério do Meio Ambiente [MMA], 2016). Esta análise corroborou que, embora as $\mathrm{SbN}$ se adequem para responder às complexas questões ali existentes, é preciso superar obstáculos no ambiente institucional. Tendo isto em vista e considerando a hipótese levantada, foram analisados o desempenho e as pautas do Comitê de Bacia Hidrográfica do Alto Tietê e do Consejo de Cuenca del Valle de México (Campos, 2004, 2008; Campos \& Fracalanza, 2010; Comitê de Bacia Hidrográfica do Alto Tietê [CBH-AT], 2013; Hernández-Suárez, 2011; México, 2020a; México, 2020b; Romero Navarrete, 2020; Simionato, 2020).

A seguir, apresentam-se os resultados obtidos a partir da pesquisa e leitura crítica deste material e encaminha-se a discussão.

\section{RESULTADOS E DISCUSSÃO}

\section{Evolução conceitual e difusão}

O conceito de SbN vem evoluindo desde sua apresentação em 2012 (IUCN , 2012), com a inclusão de aspectos relevantes para a discussão aqui desenvolvida. 
Uma mudança significativa foi que, após a ênfase dada inicialmente ao papel dos serviços ecossistêmicos no processo de resposta a desafios sociais e ambientais, passou-se a reconhecer os serviços ambientais, o que é extremamente relevante (Cohen-Shacham et al., 2016; Fraga \& Sayago, 2020). No caso da drenagem urbana, ao se reconhecer o papel que indivíduos ou grupos podem desempenhar, adotando $\mathrm{SbN}$ em terrenos particulares ou mesmo em áreas públicas, como já ocorreu em São Paulo (Herzog \& Antunã Rozado, 2020), reforça-se a importância de tê-los presentes nos processos de cocriação e governança para melhores resultados.

Outra importante alteração, ocorrida na gestão das águas, foi que, após o destaque inicial do papel das SbN no ciclo da água e na disponibilidade e qualidade deste recurso (WWAP UN-Water, 2018), foram-lhes sendo agregadas, pouco a pouco, outras potencialidades como seu desempenho no gerenciamento de riscos, na adaptação a eventos extremos e na promoção de resiliência urbana, apontadas como "cobenefícios secundários" (WWAP UN-Water, 2020). Recentemente, também foi reconhecida a necessidade de se mensurar e divulgar o valor da água (WWAP UN-Water, 2021), incluindo-o na tomada de decisões, algo fundamental, que pode interferir no processo de adoção de SbN na drenagem urbana se o valor das águas pluviais for reconsiderado.

Esta evolução conceitual, assim como os resultados das experiências realizadas, permitiu não apenas um detalhamento maior do uso das $\mathrm{SbN}$ e o reconhecimento de suas potencialidades, mas também a percepção de que novas soluções demandam novos procedimentos. Embora alguns tipos de SbN já sejam aplicados em alguns locais, seu uso com novo propósito, prestando serviços ambientais e aumentando a resiliência urbana, é algo relativamente novo, o que demanda alterações nos processos de criação e governança, sob o prisma da colaboração (McCormick, 2020).

Uma destas alterações refere-se à inclusão de vários segmentos instituições públicas, companhias privadas, academia, sociedade civil, etc. -, no processo criativo e de tomada de decisão (Caitana et al., 2020), o que não se verifica atualmente. Trata-se de adotar um processo de cocriação, em que todos os envolvidos colaboram ativamente, trazendo uma expertise diferente, complementar, o que propicia aprendizados ao longo do processo e possibilita chegar a um resultado de melhor qualidade (Morello et al., 2018). A cocriação alinha-se com uma boa governança, na qual "novos caminhos, teóricos e práticos, são propostos e adotados visando estabelecer uma relação alternativa entre o nível governamental e as demandas sociais e gerir os diferentes interesses existentes" (Campos \& Fracalanza, 2010, p. 368); isto implica adotar novas estruturas e novos processos, como ocorrido na formatação dos colegiados de gestão de recursos hídricos. 
Estas experiências de construção coletiva, além de permitir inovar, constituem "uma estratégia necessária para angariar mais apoio e engajamento dos atores envolvidos, legitimidade perante a liderança e, consequentemente, melhores condições para continuação e disseminação das práticas." (Cavalcante, 2019, p. 22)

Neste sentido, diferentes estratégias, métodos e ferramentas têm sido desenhados e implementados para promover o engajamento dos diferentes atores no processo de cocriação de $\mathrm{SbN}$; alguns destes materiais, com apoio financeiro da União Europeia - UE, foram, inclusive, compilados em guias para facilitar o processo e estão disponíveis virtualmente (Morelo et al, 2018; Urban Nature Labs Project [UNaLab], 2020).

Além da UE, outras organizações internacionais como agências das Nações Unidas, a agência alemã GIZ (Deutsche Gesellschaft für Internationale Zusammenarbeit), a rede global Governos Locais para a Sustentabilidade - ICLEI, a UICN, a organização The Nature Conservancy, vêm contribuindo para disseminar o tema ao realizar acordos de cooperação técnica com países latino-americanos, como Argentina, Brasil, Chile, Colômbia e México, por meio dos quais têm realizado eventos para compartilhar sua expertise e contribuído no desenvolvimento de projetos-piloto.

Importante destacar ainda o papel desempenhado por profissionais de instituições de ensino e pesquisa que, além de contribuir para difundir e ampliar a adoção de SbN em projetos, têm colaborado com ações desenvolvidas no âmbito destes acordos de cooperação técnica e participado como representantes nos colegiados aqui tratados.

\section{SbN na América Latina}

A pesquisa sobre o tema na América Latina mostrou que ainda há muito por fazer para consolidar as propostas e tornar o emprego de SbN algo frequente. Contudo, é possível observar que tais soluções vêm ganhando força na medida em que planos de adaptação a eventos extremos, nacionais e locais, estão sendo elaborados, adotando-as como estratégia. No caso da infraestrutura verde, especificamente, pode-se observar um aumento em sua utilização em algumas cidades, como apontado antes, embora muito aquém do desejável; existem algumas possíveis respostas a esta morosidade, ou dificuldade, para incorporá-la dentre as quais se pode mencionar: a ausência de uma visão sistêmica, a falta de compreensão sobre como integrá-la à infraestrutura convencional, em escala; a existência de mitos e incertezas sobre seu funcionamento e sobre os custos envolvidos; ou ainda, o fato de que, na maioria das vezes, diferentes departamentos, dispersos no organograma administrativo, são responsáveis por algum aspecto envolvido na drenagem urbana. Este conjunto de fatores reforça a tendência prévia de resistir ao novo. 
11. No Brasil, o governo federal com apoio da União Europeia, promoveu os seguintes seminários:

"Soluções baseadas na natureza e urbanização sustentável", em 2015; "Inovar as cidades com soluções baseadas na natureza: cocriar conhecimento sobre soluções baseadas na natureza com os diálogos setoriais UE-Brasil", em 2016; "Promovendo a natureza urbana para cidades mais resilientes", em 2018; e "O desafio da água e as cidades", em 2020. No México, no âmbito da cooperação técnica entre o governo mexicano e o governo alemão, por meio da GIZ, foi promovido o Foro Internacional sobre Infraestructura verde y cambio climático, em 2018. Posteriormente, com apoio da Cátedra UNESCO IMTA, foram promovidos - Seminário "Soluciones basadas en la naturaleza para la gestión hídrica en Latinoamérica", em 2020, e o Colóquio internacional "Soluciones basadas en la naturaleza para la gestión hídrica", em 2021. (Guillaume Courty, Centeno Alvarez, \& Noriega Bernabé, 2021; Instituto Mexicano de Tecnología del Agua [IMTA], 2021).
No Brasil e no México, em linhas gerais, o processo assemelha-se ao de outros países da região, constatando-se o papel importante dos acordos de cooperação técnica para o aprofundamento do tema ${ }^{11} \mathrm{e}$, de modo prático, para criar subsídios à elaboração de planos nacionais e à formulação de roteiros para orientar os governos subnacionais.

No caso brasileiro, as SbN têm sido vinculadas à promoção de cidades mais sustentáveis e resilientes. Alinha-se com isto as Estratégias de Adaptação de Cidades, elaboradas no âmbito do Plano Nacional de Adaptação às Mudanças do Clima, dentre as quais constam o fortalecimento de ações de drenagem urbana sustentável e a adoção de SbN (Brasil, 2016). Em 2020, tais ações foram reforçadas pelo lançamento do Observatório de Inovação para Cidades Sustentáveis - OICS, uma plataforma virtual que organiza e exibe conteúdos sobre soluções urbanas sustentáveis e inovadoras, com especial ênfase para as SbN.

Outro campo em destaque no país, que tem incorporado SbN ou pelo menos evidenciado preocupação com as águas pluviais, é a gestão das águas. Neste sentido, foi adicionado um novo objetivo à Política Nacional de Recursos Hídricos, tratando de "incentivar e promover a captação, a preservação e o aproveitamento de águas pluviais" (Brasil, 2017), o que, embora não vincule o emprego de $\mathrm{SbN}$, a médio e longo prazo, poderá trazer benefícios e aumentar os investimentos no setor. Adicionalmente, o Programa Nacional de Revitalização de Bacias Hidrográficas - PNRBH, parte do Plano Nacional de Recursos Hídricos - PNRH, 2022-2040, ambos em elaboração pela Agência Nacional de Águas e Saneamento Básico - ANA, apoia-se nos serviços ambientais, prestados pelas $\mathrm{SbN}$, visando garantir usos múltiplos e promover segurança hídrica. Apesar destes avanços, o novo marco legal do saneamento básico (Brasil, 2020) não faz menção a SbN, mantendo o amplo uso da infraestrutura convencional; o que apontou foi a obrigatoriedade da ANA editar normas para a regulação dos serviços públicos do setor no país, dentre os quais a drenagem e o manejo de águas pluviais urbanas, previsto para $02^{\circ}$ semestre de 2022. Considerando que à ANA cabe a elaboração do PNRH/PNRBH e das normas para drenagem, pode-se especular se haverá espaço para maior compatibilização entre estas áreas.

No caso mexicano, por sua vez, a pesquisa mostrou que vêm sendo realizados esforços em nível federal para unir as agendas do desenvolvimento urbano, do meio ambiente e das mudanças climáticas. Neste contexto, evidencia-se o Programa de Protección del Clima en la Política Urbana de México - Ciudades y cambio climático (Ciclim), 20172021, desenvolvido no âmbito da cooperação técnica entre os governos mexicano e alemão, que propôs, dentre outras ações, que haja maior integração da gestão do uso do solo urbano e da gestão do meio ambiente, assim como sejam efetuadas adaptações no planejamento da infraestrutura convencional, incorporando modelos "mais verdes". 
12. Este instrumento contempla um conjunto de regras de ocupação do solo, aplicáveis a cada lote privado por seu proprietário, visando a aprovação de um projeto de edificação ou reforma

- em áreas pré-definidas pela Lei no 16.402/2016, chamadas

"perímetros de qualificação ambiental", e em lotes com área superior a $500 \mathrm{~m}^{2}$. Embora a lei não faça referência ao termo SbN, é possível observar que, no leque de opções possíveis de serem adotadas, encontram-se soluções que se classificam como tal.

13. A mídia tem veiculado informações sobre a implementação de SbN em São Paulo, tanto para aumentar cobertura vegetal como melhorar a drenagem de águas pluviais. Interessante observar que o termo "jardim de chuva" tem se tornado um guarda-chuva no qual cabem outras diferentes soluções: biovaletas, "vagas verdes", canteiro pluvial. Notícias publicadas no jornal Folha de São Paulo, em maio e junho de 2021, disponíveis em: <https://www. prefeitura.sp.gov.br/ cidade/secretarias/subprefeituras/ se $/$ noticias $/ p=108463>$. Acesso em: 04 dez. 2021. <https://www. prefeitura.sp.gov.br/ cidade/secretarias/subprefeituras/ noticias/index. php?p=307357 $>$.

Acesso em: 04 dez. 2021.

$<$ https://www1.folha.uol. com.br/cotidiano/2021/06/ prefeitura-quer-expandir-jardinse-minipracas-para-prevenirenchentes-em-sp.shtml>. Acesso em: 04 dez. 2021.
Foram elaborados ainda alguns guias para orientar a ação dos governos municipais como o documento "Implementação de infraestrutura verde como estratégia para a mitigação e adaptação às mudanças climáticas em cidades mexicanas: roteiro" (México, 2018).

No que diz respeito à gestão das águas, embora a recente revisão da Lei de Águas Nacionais (México, 2020a) não tenha feito menção à SbN, o Programa Nacional Hídrico - PNH, 2020-2024 (México, 2020b), que a ela sucedeu, superou esta deficiência, propondo que se adote infraestrutura verde.

Estes avanços verificados na escala nacional, ainda recentes, repercutiram em alguma medida na escala local, como será exposto a seguir.

\section{SbN aplicadas no contexto paulistano e capitalino}

No município de São Paulo, constata-se a inclusão de propostas alternativas, como as $\mathrm{SbN}$, no tratamento da questão ambiental e urbana. Em parte, isto vem ocorrendo para atender às diretrizes do Plano Diretor Estratégico de São Paulo (São Paulo, 2014) como, por exemplo, a necessidade de se adotar medidas de mitigação e adaptação às mudanças climáticas e ações para reduzir enchentes e minimizar os efeitos das ilhas de calor. Desde sua aprovação, leis e planos vêm sendo elaborados para dar seguimento à política urbana e ambiental do município. Relaciona-se a isto a Lei de parcelamento, uso e ocupação do solo (São Paulo, 2016), que propôs um novo instrumento, visando a melhoria ambiental na escala urbana quanto a drenagem, microclima e biodiversidade, denominado quota ambiental ${ }^{12}$. Também é relevante o Plano de Saneamento Básico do município, no qual são reconhecidos os impactos não desejados da infraestrutura convencional e a existência de uma "nova abordagem", que propõe "estruturas de contenção multifuncionais, combinadas com propósitos de paisagismo ou recreação", ao invés dos sistemas intensivos de contenção, por serem "mais acessíveis e viáveis" e "mais facilmente distribuídos pela cidade" (São Paulo, 2019, p. 58). Cabe destacar ainda o Plano de Ação Climática do Município de São Paulo - PlanClima SP (São Paulo, 2021a), que contém estratégias para tornar a cidade mais resiliente; uma delas, denominada "adaptar a cidade de hoje para o amanhã", propõe o emprego de SbN, o que já foi incorporado pelo Plano de Metas, período 2021-2024 (São Paulo, 2021b). Contudo, embora na prática se observe um aumento do número de "jardins de chuva" pela cidade ${ }^{13}$, as obras convencionais preponderam e está prevista a construção de 14 novos "piscinões" - estrutura convencional subterrânea para acumular a água da chuva.

Na Cidade do México, por seu turno, há algum tempo vêm sendo adotadas ações para aumentar a resiliência urbana, destacando-se o Programa de Ação Climática da Cidade do México e a Estratégia Local de Ação Climática, 2014-2020 (CDMX, 2014), em processo de revisão 
e atualização, e a Estratégia de Resiliência para a Cidade do México (CDMX, 2016b), nos quais se identifica a busca por alternativas para a captura, retenção, regulação e infiltração de água de chuva e prevenção de inundações. Recentemente, o Programa de Governo da Cidade de México, 2019-2024, apresentou ações para a drenagem de águas urbanas que contemplam SbN; desde então, ao lado de melhoramentos e expansão da infraestrutura convencional de drenagem das águas combinadas, desenvolve-se um trabalho de saneamento e recuperação de rios da cidade, visando restabelecer sua capacidade para dar vazão às águas de chuva e reduzir os riscos de inundação (CDMX, 2019). Neste contexto, o Plano Diretor de Infraestrutura Verde da Cidade do México, 2019-2024, é uma peça-chave.

Paralelamente, considerando a escala do edifício, o governo da Cidade do México vem estimulando a adoção de tetos verdes para melhorar o conforto térmico das edificações, diminuir ilhas de calor e captar e armazenar água de chuva; como parte desta política, vem instalando tetos verdes em edifícios públicos (CDMX, 2016a). Tal proposta soma-se ao programa de instalação de Sistemas de captación de agua de lluvia - SCALL, obrigatória, desde 2003, em todas edificações novas, cuja área construída esteja entre $5.000 \mathrm{~m}^{2}$ e $10.000 \mathrm{~m}^{2}$.

À parte este conjunto de marcos legais, planos e propostas locais, a pesquisa permitiu identificar características do setor que condicionarão a adoção de SbN na drenagem nos contextos paulistano e capitalino.

Em São Paulo, os estudos evidenciaram que a drenagem urbana é preterida com relação aos demais serviços de saneamento básico, inclusive o esgotamento sanitário, que é realizado em sistema separado. Além disto, considerando que a microdrenagem, como citado, cabe ao governo municipal, a macrodrenagem, ao governo estadual, e que se formou um complexo hidráulico-sanitário para atender às necessidades da metrópole, fica evidente a complexidade de sua gestão. Por isto, alguns documentos têm salientado que seria melhor adotar a bacia hidrográfica como unidade de planejamento e gestão dos sistemas de drenagem (São Paulo, 2019) e alertado para a necessidade de articular, no âmbito do CBH-AT, "ações conjuntas de conservação e recuperação e fiscalização ambiental entre os municípios da Região Metropolitana de São Paulo e a Secretaria Estadual de Infraestrutura e Meio Ambiente" (São Paulo, 2014).

Na Cidade do México, o sistema de drenagem combinado tem importante posição uma vez que administrar as águas na bacia é uma questão de sobrevivência para a urbe; por isto, o setor vem recebendo não sem críticas - vultosos recursos para sua manutenção e continua ampliação. Aqui, apesar de se ter adotado um sistema combinado de drenagem, a gestão também é fragmentada e complexa. 


\section{SbN e drenagem em São Paulo e na Cidade do México: desafios e oportunidades}

Neste cenário, em que as SbN estão sendo incorporadas nos planos locais de adaptação a eventos extremos e nas propostas de drenagem urbana sustentável, seria possível aventar que os entraves a sua adoção já estivessem superados. Entretanto, a existência de marcos legais ou planos, per se, não é suficiente para que a implementação ocorra nem que seja bem-sucedida.

No caso da implementação do Plano Diretor de Infraestrutura Verde, em curso na Cidade do México, por exemplo, um desafio enfrentado tem sido a atuação conjunta entre departamentos; como apontado por técnicos da Secretaria de Meio Ambiente, tem sido necessário um esforço contínuo - destes especialistas - para convencer os outros departamentos da administração envolvidos de que adotar SbN pode ser extremamente benéfico. Já no caso do PlanClima SP, um desafio enfrentado foi o trabalho conjunto entre diferentes secretarias no processo de elaboração das propostas, o qual, para maiores avanços, deverá continuar nas próximas fases.

Os desafios de tais experiências, entretanto, envolvem apenas a integração de instâncias administrativas no âmbito municipal. Como ficam os demais municípios da Bacia do Alto Tietê ou do Vale do México, impactados pelas ações destas metrópoles? E os demais níveis de governo ou os outros beneficiários? Não serão envolvidos no tratamento da questão? Nestas condições, é difícil adotar processos de cocriação relacionados à $\mathrm{SbN}$ ou governança colaborativa; mas se é fundamental adotar um novo processo, não apenas para alcançar melhores resultados, mas também para prestar adequadamente serviços ambientais, conferindo maior resiliência às cidades e seu território, qual seria um caminho alternativo a se tomar?

Uma oportunidade aberta é a existência dos citados colegiados - $\mathrm{CBH}-$ -AT e CCVM-, os quais, tendo em vista sua escala de atuação e objetivos, poderiam inserir, de modo mais incisivo, o tema "SbN na drenagem urbana" em suas pautas. Embora tenham composição diferente, são colegiados mistos e participativos, o que favoreceria uma discussão mais ampla sobre o assunto; também contam com unidades menores Subcomitês de bacia e Comisiones de cuenca -, o que pode ser útil para desenvolver processos de cocriação; além disto, poderiam contribuir com algum recurso financeiro, provindo, por exemplo, da cobrança pelo uso da água, para fomentar estudos ou capacitar mão-de-obra relacionada à SbN - algo positivo especialmente considerando a baixa capacidade de investimento de alguns municípios ou grupos sociais.

No CBH-AT, o tema SbN já foi abordado e, em novembro de 2020, foi criado o grupo de trabalho Eventos Extremos com o objetivo de 
elaborar uma proposta com medidas e procedimentos de gestão em eventos climáticos e meteorológicos extremos - especificamente secas e precipitações extremas. O CCVM, por sua vez, deverá ser impactado, sobretudo, pela última revisão da Lei de Águas Nacionais e pelo Programa Nacional Hídrico (México, 2020b) que, ao indicar o uso de infraestrutura verde, poderá impulsionar sua adoção.

Um aspecto relevante com relação a tais arranjos é que, embora sigam um marco legal imposto a priori - pelo governo estadual, no caso do CBH-AT, e pelo governo federal, no caso do CCVM -, a definição de seu Estatuto e de alguns procedimentos sofrem alterações ao longo do tempo para atender a novas demandas (Simionato, 2020), fato que amplia o potencial destes arranjos colaborativos; no caso dos Consejos de Cuenca do México, porém esta flexibilidade é relativa, estando bastante condicionada à Lei de Águas Nacionais e seus regulamentos.

Entretanto, embora venham ocorrendo avanços nestes colegiados e eles possam ser vistos como oportunidade aberta, na prática, estão em processo de construção coletiva e aperfeiçoamento. Assim, os mesmos desafios existentes para a boa governança das águas - alcançar a almejada integração, superar os limites da negociação técnico-social -, assinalados por Campos e Fracalanza (2010), permanecem e são extensíveis para a adoção de processos de cocriação e governança colaborativa relacionados às $\mathrm{SbN}$.

Além disto, embora tais instâncias envolvam diferentes segmentos, sua composição e representatividade, assim como algumas operações internas, podem ser questionadas. No CBH-AT, ao longo do processo, é possível verificar assimetria de poder, reforçada por alguns acordos e convenções - como a distribuição de cargos na composição da diretoria (Campos, 2008) ou a categorização dos setores que compõe o segmento "sociedade civil", o que dificulta a coesão do grupo (Campos, 2004, 2008). No CCVM também é possível constatar assimetria de poder e problemas de representação (México, 2020b); um exemplo, foi a nomeação do representante da Associação Nacional de Empresas de Água e Saneamento - ANEAS, um usuário, como chefe da Conagua, um órgão federal, entre 2012 e 2017 (BM, 2013).

Assim, ainda que estes colegiados possam ser aproveitados como plataforma para o processo de cocriação envolvendo SbN, é necessário promover seu aprimoramento, garantindo que a estrutura existente seja mais adaptativa. Além disto, o nível de engajamento da sociedade civil e a credibilidade das instituições públicas envolvidas precisam estar elevados para que os resultados sejam relevantes. A adoção de SbN na drenagem urbana demanda, além de um quadro institucional mais adaptado às características e demandas das SbN, vontade política e social. 


\section{CONSIDERAÇÕES FINAIS}

Os eventos extremos estão ocorrendo, cada vez mais, com maior frequência e intensidade, impactando a população e as infraestruturas urbanas, especialmente, nas bacias mais urbanizadas e metropolizadas.

Para fazer frente aos impactos de tais eventos, é fundamental que haja uma mudança de paradigma na relação homem e natureza, que se apoie mais na convivência do que no domínio. Isto se aplica tanto nas ações para promover uma drenagem urbana sustentável, de modo constante, quanto nas ações para responder a episódios de inundações críticas. Neste sentido, ganham destaque as soluções baseadas na natureza que, alinhadas a este novo paradigma, contribuem para adaptar as áreas urbanizadas para que acomodem melhor as águas pluviais, colaborando para a resiliência urbana.

Na América Latina e, em especial, nas áreas de estudo, conforme apresentado, as SbN vêm sendo adotadas na drenagem urbana sustentável e como estratégia a adaptação das cidades a eventos extremos, assim como têm permeado as políticas brasileira e mexicana de ação climática e de gestão das águas, embora em estágio inicial. Destacam-se, neste processo, os acordos de cooperação técnica que vêm sendo realizados e os trabalhos desenvolvidos em importantes instituições de ensino e pesquisa, apontados anteriormente, os quais têm contribuído para difundir e ampliar a adoção de SbN nos projetos.

Contudo, apesar dos aspectos positivos das SbN e das iniciativas em curso em São Paulo e na Cidade do México, existem desafios a enfrentar para ampliar sua implementação na drenagem urbana. Por um lado, no que diz respeito à atuação governamental, responsável pela regulação do setor e pela efetivação de ações estruturais e não estruturais, é necessário superar a visão mecanicista por parte dos tomadores de decisão e promover as mudanças necessárias nas estruturas administrativas que tratam desta matéria; entretanto, isto implica, sobretudo, vontade política. Por outro lado, o fato de que as SbN têm por característica serem localmente adaptadas, apesar de funcionarem em rede, requer a adoção de processos de cocriação e governança colaborativa, que demandam uma plataforma participativa e flexível, o que contrasta com o desenho das estruturas existentes. A constituição de um ambiente aberto e adaptativo para responder às demandas do setor, em um momento de incertezas, além de propiciar a inovação, também pode contribuir para obter maior engajamento dos atores envolvidos, levando a melhores - e mais legítimos - resultados.

Sendo assim, entende-se como um caminho a ser seguido, capaz de responder a alguns destes desafios, a inclusão deste tópico na agenda dos colegiados existentes nas áreas de estudo - CBH-AT e do CCVM -, mesmo que estes ambientes estejam em processo contínuo de 
construção. São instâncias apoiadas na participação e na colaboração de diferentes segmentos, que, inclusive, têm dentre seus objetivos promover ações para combater causas e efeitos adversos de inundações e estiagens, incluídos os eventos hidrológicos críticos. No caso do $\mathrm{CBH}-\mathrm{AT}$, inclusive, a questão já foi abordada, mas necessita ganhar maior relevância.

Neste sentido, a possibilidade de contar com o CBH-AT e o CCVM para tratar de SbN na drenagem urbana parece auspiciosa e com múltiplos benefícios uma vez que: por um lado, pode-se aproveitar arranjos já instituídos, com múltiplos atores, e com experiência acumulada em processos participativos na gestão da água, tanto na negociação como na construção de consensos; e, por outro, a adoção de processos de cocriação, nestes colegiados, pode contribuir para aprimorar sua própria estrutura e os procedimentos neles desenvolvidos, melhorando a governança da água.

Nos casos analisados, há um cenário favorável para a adoção de SbN na drenagem urbana e como estratégia para adaptação das cidades a eventos extremos. Entretanto, por se tratar de iniciativas muito recentes, ainda há um caminho considerável a percorrer para se poder avaliar os resultados.

\section{REFERÊNCIAS}

Banco Mundial (BM). (2013). Agua urbana en el Valle de México. ¿Un camino verde para mañana? Cidade de México: Conagua, Banco Mundial, Gobierno de España, ANEAS, CAEM, SACMEX. Marzo.

Caitana, B., Ferreira, I. \& Campos, P. F. de. (2020). Co-criação de SbN: envolvendo comunidades e oportunidades de diálogo Europa-Brasil. Revista de Parcerias Estratégicas. Brasília, CGEE, v.25, n50, jan-jun, p. 189-216.

Campos, V.N.O. (2001). Metropolização e recursos hídricos na América Latina: o caso da Região Metropolitana de São Paulo e da Zona Metropolitana da Cidade do México: 1970 a 2000. (Dissertação de Mestrado). Programa de Pós-graduação em Integração da América Latina, Universidade de São Paulo, São Paulo.

Campos, V.N.O. (2004). Gestión de Recursos Hídricos y la Participación de la Sociedad Civil Organizada en la Cuenca Hidrográfica Alto Tietê. In: Warner, J. \& Moreyra, A. Conflictos y participación. Uso múltiple del Agua. Montevideo, Uruguay: Editorial Nordan-Comunidad. pp.145-156.

Campos, V.N.O. (2008). O Comitê de Bacia Hidrográfica do Alto Tietê e o Consejo de Cuenca del Valle de México: potencialidades e limites da gestão participativa da água. 1980-2005. (Tese de Doutorado). Programa de Pós-graduação em Integração da América Latina, Universidade de São Paulo, São Paulo.

Campos, V.N.O. \& Fracalanza, A.P. (2010). Governança das águas no Brasil: conflitos pela apropriação da água e a busca da integração como consenso. Revista Ambiente e Sociedade. Campinas, v. XIII, n.2, jul-dez, pp. 365-382.

Cavalcante, P. (org.) (2019). Inovação e políticas: superando o mito da ideia. Brasília: IPEA.

Cohen-Shacham, E., Walters, G., Janzen, C. \& Maginnis, S. (eds.) (2016). Naturebased solutions to address global societal challenges. Gland, Switzerland: IUCN. 
Delosríos-White, M. I., Roebeling, P., Valente, S. \& Vaittinen, I. (2020). Mapping the life cycle co-creation process of nature-based solutions for urban climate change adaptation. Resources (MDPI journal) 9, 39. 26p.

Fraga, R. \& Sayago, D. A. V. (2020). Soluções baseadas na Natureza: uma revisão sobre o conceito. Revista de Parcerias Estratégicas. Brasília: CGEE. v.25, n50, janjun, pp. 67-82.

Giannotti, E., Vásquez, A., Galdámez, E., Velásquez, P., \& Devoto, C. (2021). Planificación de infraestructura verde para la emergencia climática: aprendizajes desde el proyecto "Stgo+", Santiago de Chile. Cuadernos de Geografía: Revista Colombiana de Geografía, 30 (2), pp. 359-375.

Guillaume Courty, L., Centeno Alvarez, J. C, \& Noriega Bernabé, D. (coord.) (2021). Memoria. Seminario virtual Soluciones basadas en la naturaleza para la gestión hídrica en Latinoamérica. México, IMTA. Março.

Hernández-Espinosa, A. K., Otazo-Sánchez, E. M., Román-Gutiérrez, A. D., \& Romo-Gómez, C. (2021). El Sistema de drenaje de la Ciudad de México. Pädi Boletín Científico de Ciencias Básicas e Ingenierías del ICBI, 9 (17), pp. 24-30.

Hernández-Suárez, C. (2011). Nueva política del agua y herencias centralizadoras: el consejo de cuenca del Valle de México. Agricultura, sociedad y desarrollo, 8 (3), pp. 303-327.

Herzog, C. P. \& Antuña Rozado, C. (2020). Diálogo setorial EU-Brasil sobre soluções baseadas na natureza. Contribuição para um roteiro brasileiro de soluções baseadas na natureza para cidades resilientes. Bélgica: União Europeia.

International Union for Conservation of Nature (IUCN). (2012). The IUCN Programme 2013-2016. Adopted by the IUCN World Conservation Congress, September. Gland, Switzerland: IUCN.

Jiménez-Cisneros, B. (2011). Suministro y desalojo del agua de la Ciudad de México: de los aztecas al siglo XXI. Revista Digital Universitaria. Universidad Nacional Autónoma de México - UNAM. v. 12, n.10. octubre. pp.1-17.

McCormick, K. (ed.) (2020). Cities, nature and innovation: new directions. Lund: Lund University.

Morello, E., Mahmoud, I., Gulyurtlu, S., Boelman, V. \& Davis, H. (2018). CLEVER Cities Guidance on co-creating nature-based solutions. PART I - Defining the cocreation framework and stakeholder engagement. Deliverable 1.1.5, CLEVER Cities, H2020 grant $n^{\circ} 776604$.

Pellegrino, P. R. M. \& Moura, N. C. B. (orgs.) (2017). Estratégias para uma infraestrutura verde. Barueri, SP: Manole.

Perló Cohen, M. \& González Reynoso, A. E. (2005). ¿Guerra por el agua en el Valle de México? Estudio sobre las relaciones hidráulicas entre el Distrito Federal y el Estado de México. Ciudad de México: Universidad Nacional Autónoma de México; Fundación Friedrich Ebert.

Portugal Del Pino, D., Borelli, S. \& Pauleit, S. (2020) Nature-Based Solutions in Latin American Cities. In: Brears, R.C. (eds) The Palgrave Handbook of Climate Resilient Societies. Palgrave Macmillan, Cham.

Romero Navarrete, L. (2020). Participación: un desafío para la Ley General de Aguas. El caso del Valle de México. In: Monroy Hermosillo, O. (Coord.) Acciones metropolitanas para la gestión sustentable del agua. Ciudad de México: ANUIES, Dirección de Producción Editorial, Universidad Autónoma Metropolitana, CRAM, El Colegio de México. pp. 67-80.

Simionato, L. Y. (2020). Estudo de caso do regime de governança colaborativa para o combate às enchentes na Bacia Hidrográfica do Alto Tietê. (Trabalho de conclusão de curso). Programa de Pós-graduação em Gestão Pública. INSPER. São Paulo.

University of Arkansas Community Design Center (UACDC). (2010). LID - Low Impact 
Development: a design manual for urban areas. Fayetteville, Arkansas: UACDC.

Urban Nature Labs Project (UNaLab). (2021) UNaLab Co-Creation Toolkit: tools for co-creation. Disponível em: https://unalab.enoll.org/. Acesso em 11/junho/2021.

United Nations World Water Assessment Programme (WWAP UN-Water). (2018). The United Nations World Water Development Report 2018: Nature-Based Solutions for Water. Paris, UNESCO.

United Nations World Water Assessment Programme (WWAP UN-Water). (2020). The United Nations World Water Development Report 2020: Water and Climate Change. Paris, UNESCO.

United Nations World Water Assessment Programme (WWAP-UN-Water). (2021). The United Nations World Water Development Report 2021: Valuing Water. Paris. UNESCO

World Bank (WB). (2016). Flood Risk Management Support Project for the Autonomous City of Buenos Aires, Argentina. The World Bank Group.

Yerovi López, D. J. (2015). Cidade e natureza: conexões e infraestrutura verde. Dois bairros em Quito, Equador. (Dissertação de mestrado). Universidade Federal de Santa Catarina. Florianópolis.

\section{Documentos}

Agência Nacional da Água (ANA) (Brasil). (2018). Relatório final do $8^{\circ}$ Fórum Mundial da Água / Agência Nacional de Águas, Agência Reguladora de Águas, Energia e Saneamento Básico do Distrito Federal, Conselho Mundial da Água. Brasília: ANA.

Agência Nacional de Águas e Saneamento Básico (ANA) (Brasil) (2020). Conjuntura dos recursos hídricos no Brasil 2020: informe anual / Agência Nacional de Águas e Saneamento Básico. -- Brasília: ANA.

Brasil (União). (1997). Lei federal n 9433/1997, que institui a Política Nacional de Recursos Hídricos e cria o Sistema Nacional de Gerenciamento de Recursos Hídricos. Publicada no Diário Oficial da União, em 09 de janeiro de 1997.

Brasil (União). (2017). Lei federal n 13.501/2017, que altera o art. $2^{\circ}$ da Lei $n^{\circ} 9.433$, de 8 de janeiro de 1997, que institui a Política Nacional de Recursos Hídricos, para incluir o aproveitamento de águas pluviais como um de seus objetivos. Publicada no Diário Oficial da União, em 31 de outubro de 2017.

Brasil (União). (2020). Lei federal n 14.026, de 15 de julho de 2020, que atualiza o marco legal do saneamento básico e atribui à Agência Nacional de Águas e Saneamento Básico (ANA) competência para editar normas de referência sobre o serviço de saneamento.

Cidade do México (CDMX). (2014). Estrategia Local de Acción Climática, 2014-2020. $1^{\text {a }}$ edición. Ciudad de México: Secretaria de Medio Ambiente - SEDEMA; Centro Mario Molina. Julio.

Cidade do México (CDMX). (2016a). Ciudad de México sustentable: verde, móvil, educativa, recreativa. $1^{\text {a }}$ edición. Ciudad de México, Secretaria de Medio Ambiente - SEDEMA.

Cidade do México (CDMX). (2016b). Estrategia de Resiliencia CDMX: transformación adaptativa, incluyente y equitativa. Ciudad de México, Secretaria de Medio Ambiente - SEDEMA / 100 Resilient Cities, Septiembre.

Cidade do México (CDMX). (2019). Programa de Gobierno de la Ciudad de México, período 2019-2024. Ciudad de México.

Cidade do México (CDMX). (2020). Segundo Informe de Gobierno. Agosto 2019 a Julio 2020. Ciudad de México: Secretaria de Medio Ambiente - SEDEMA.

Comitê de Bacia Hidrográfica Alto Tietê (CBH-AT) (2013). Estatuto. Aprovado pela 
Deliberação CBH-AT n 02 de 04/06/2013. São Paulo. Publicado no Diário Oficial do Estado, em 06 de junho de 2013 - Caderno Executivo I - Página 136

Departamento de Águas e Energia Elétrica (DAEE). (São Paulo). (2014). Terceiro Plano Diretor de Macrodrenagem da Bacia do Alto Tietê - PDMAT 3. Consórcio Cobrape, ENGECORPS e Maubertec. São Paulo, junho.

México (Federação). (2018). Implementación de Infraestructura Verde como estrategia para la mitigación y adaptación al cambio climático en ciudades mexicanas, hoja de ruta. Ciudad de México: SEDATU; SEMARNAT; GIZ. Septiembre.

México (Federação). (2020a). Lei de Águas Nacionais - LAN, 1992. Revisão publicada no Diário Oficial da Federação- DOF, em 06 de janeiro de 2020.

México (Federação). (2020b). Programa Nacional Hídrico, 2020-2024. Elaborado por Comisión Nacional del Água (CONAGUA) - Secretaria de Medio Ambiente y Recursos Naturales (SEMARNAT). Decreto federal de 30 de dezembro de 2020.

Ministério do Meio Ambiente (MMA). (Brasil). (2016) Plano Nacional de Adaptação à Mudança do Clima. Vol II: Estratégias setoriais e temáticas. Portaria MMA n 150 de 10 de maio de 2016. Brasília, MMA.

São Paulo (Cidade). (2014) Lei n 16.050, de 31 de julho de 2014. Aprova a Política de Desenvolvimento Urbano e o Plano Diretor Estratégico do Município de São Paulo e revoga a Lei no 13.430/2002. Publicada no Diário Oficial do Município, em $1^{\circ}$ de agosto de 2014.

São Paulo (cidade) (2016). Lei n 16.402, de 22 de março de 2016. Disciplina o parcelamento, o uso e a ocupação do solo no Município de São Paulo, de acordo com a Lei n 16.050/2014 - Plano Diretor Estratégico. Publicada no Diário Oficial do Município, em 23 de março de 2016.

São Paulo (cidade). (2019) Comitê Gestor dos Serviços de Água e Esgoto da Capital Paulista. Plano Municipal de Saneamento Básico de São Paulo - PMSB 2019/2020. Anexo único integrante do Decreto n 58.778, de 30 de maio de 2019. Publicado no Diário Oficial do Município - DOM, em 31 de maio de 2019.

São Paulo (cidade) (2021a). Plano de Ação Climática do Município de São Paulo 20202050 - PlanClima SP. São Paulo.

São Paulo (cidade) (2021b). Secretaria de governo municipal. Programa de Metas 2021-24. Versão final participativa. São Paulo.

São Paulo (estado) (1991). Lei estadual n 7663, de 30 de dezembro de 1991.

Estabelece normas de orientação à Política Estadual de Recursos Hídricos bem como ao Sistema Integrado de Gerenciamento de Recursos Hídricos no estado de São Paulo. (Atualizada até a Lei n 16.337/2016). Publicada no Diário Oficial do Estado, em 31 de dezembro de 1991. p 2.

\section{Eventos online}

Hernández Solís, M. (2021). Plan de Infraestructura Verde para la Ciudad de México: Gestión, Retos y Beneficios. Congreso Internacional de Parques Urbanos. Parques Sudamérica. Guayaquil, Ecuador. Mayo. (Disponível em: Plan de infraestructura verde para la Ciudad de México: Gestión, Retos y Beneficios - Maritza H. - YouTube. Acesso em 31 de julho de 2021).

Instituto Mexicano de Tecnología del Agua (IMTA) / UNESCO. (2021) Coloquio internacional Soluciones basadas en la naturaleza para la gestión hídrica. Várias sessões realizadas no mês de junho de 2021. Disponível no canal IMTA do Youtube (3) Canal IMTA - YouTube). Acesso em junho de 2021. 


\section{Valéria Nagy de Oliveira Campos}

Doutora em Integração da América Latina (PROLAM-USP, 2008). Arquiteta e Urbanista (FAU-USP, 1993) / s.af. arquiteta autônoma E-mail:valnagyc@alumni.usp.br ORCID: https://orcid.org/0000-0002-9223-1919

Recebido em: 09/08/2021.

Aceito em: 04/12/2021. 